\title{
Strengthening of Different Types of Slabs with Composite-Reinforced Mortars (CRM)
}

\author{
Tommaso D’Antino, Angela S. Calabrese, Carlo Poggi, Pierluigi Colombi, \\ Giulia Fava and Massimiliano Bocciarelli
}

\begin{abstract}
A great number of buildings built in Europe in the second half of the last century are currently in need of strengthening and retrofitting. One of the more frequent issues is the weakness of the slabs and, in particular, of the intrados covering layer (usually a plaster) and/or of the clay non-structural elements employed to decrease the overall slab weight. The application of composite-reinforced mortar (CRM) systems represents a fast and easy solution to address these weaknesses. Therefore, they are particularly attractive for applications in school buildings, to avoid long interruptions of the educational activities. In this paper, the use of CRM to strengthen different types of slabs is described and discussed on the basis of the results obtained from an experimental campaign conducted at the Politecnico di Milano.
\end{abstract}

Keywords Composite-reinforced mortars - CRM - Mechanical characterization • Slab strengthening

\section{Introduction}

Slab intrados deterioration and crumbling is one of the most frequent issues in Italian buildings built in the second half of the last century. The phenomenon is due to the presence of compression stresses that are normal to the joists direction in the slab clay hollow blocks. Compression stresses occur due to several reasons, among which thermal dilation, corrosion of the reinforcing bars, hogging moment due to plate effects, water infiltration, and so on, are the most significant. This scenario is frequent in the case of seismic events, with serious consequences for the building occupants.

Fiber-reinforced composite materials were recently introduced to the construction engineering community and were proven to be an effective solution for the strengthening and retrofitting of existing structures. Fiber-reinforced polymers (FRP) have

T. D’Antino $(\varangle)$ · A. S. Calabrese · C. Poggi · P. Colombi · G. Fava · M. Bocciarelli Architecture, Built Environment and Construction Engineering-ABC Department, Politecnico di Milano, Milan, Italy

e-mail: tommaso.dantino@polimi.it 
been studied extensively over the last few decades and are largely employed to strengthen existing reinforced concrete (RC) structures (Bakis et al. 2002). However, due to the presence of organic resins, FRP composites present a number of drawbacks (e.g. lack of vapor permeability, low resistance at relatively high temperatures, and difficulties of application on wet substrates) and are poorly compatible with concrete and masonry substrates (de Felice et al. 2014). To overcome these issues, composite materials made by high-strength fibers embedded within inorganic matrices were proposed. Among them, those including high-strength open-mesh textiles with yarn spacing lower than or equal to $30 \mathrm{~mm}$ are referred to as fiber (or fabric) reinforced cementitious matrix (FRCM) or textile-reinforced mortar (TRM) composites (ACI 549.4R 2013; CNR-DT 215 2019). FRCM/TRM composites have been gaining increasing attention due to their effective compatibility with substrates, vapor permeability, partial reversibility, and resistance to relatively high temperatures (de Felice et al. 2014).

Recently, new types of inorganic-matrix strengthening materials, comprising a composite grid embedded within an inorganic-matrix and referred to as compositereinforced mortar (CRM) materials, have been employed to strengthen the existing masonry structures (D'Antino et al. 2019). The grids used in CRMs are made by composite yarns in the warp direction and pultruded elements in the weft one. Usually, the composite yarns are twisted together and around the pultruded elements to realize a stable bi-directional grid (Fig. 1). The spacing between the yarns may vary and is higher than $30 \mathrm{~mm}$. The cross-sectional area of the laminated and pultruded elements is often higher than that of textile-reinforced mortars' fiber textile yarns (Carozzi et al. 2017; D’Antino et al. 2019).

In this paper, a study on the efficiency of three glass composite grids designed as the reinforcement of CRM material, employed for preventing the intrados crumbling hazard, is presented and discussed. The grid contribution to the vertical load induced by the intrados failure (crumbling) was studied by 16 experimental punching tests on different types of specimens simulating horizontal slab, namely a timber slab and a pre-stressed RC slab lightened with hollow clay elements. The glass composite grid was fixed at the slab intrados using anchors. The effect of grid spacing, anchorage types, and grid discontinuity on the system load-bearing capacity is investigated.
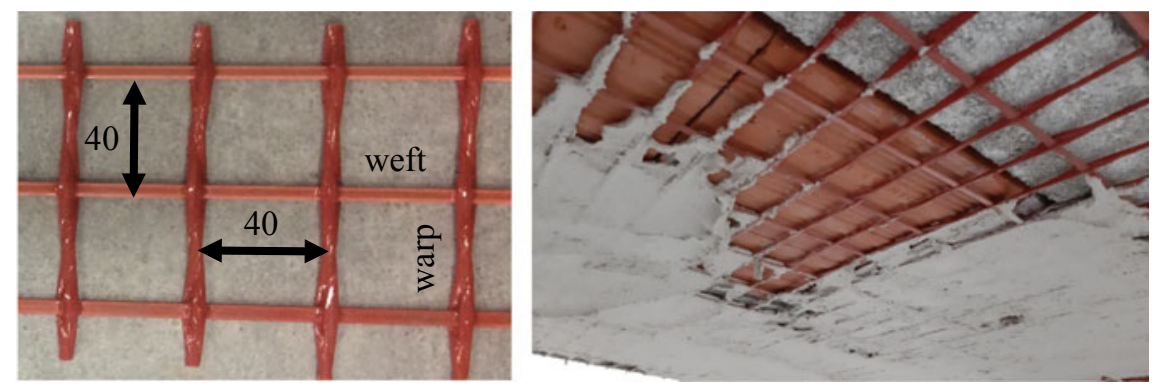

Fig. 1 Glass fiber grid (left); strengthening of a slab intrados with a glass CRM (right) 
The glass grid studied appears to be an efficient solution to solve intrados crumbling hazards. Owing to the speed of the intervention, it is particularly attractive for applications in public buildings, such as educational buildings, since they cannot remain closed for long periods of time.

\section{Mechanical Characterization of the Glass CRM}

Three different geometries (layouts) of an impregnated glass fiber composite grid, namely grids with a mesh size of $40 \times 40 \mathrm{~mm}, 40 \times 80 \mathrm{~mm}$, and $80 \times 80 \mathrm{~mm}$, are analyzed in this study.

Although the grids are all comprised of the same laminated yarns and pultruded elements, the different spacing entails for a different number of twists of the yarns, which in turn may affect the tensile properties of the grid. However, for the sake of brevity, only the mechanical characterization of the $40 \times 40 \mathrm{~mm}$ grid is reported in this paper. The square grid is made up of rectangular GFRP pultruded weft yarns and two-wire GFRP warp strands (Fig. 1). The cross-sectional area of weft and warp yarns is 5.97 and $5.71 \mathrm{~mm}^{2}$, respectively.

To measure the grid tensile properties (i.e. tensile strength, elastic modulus, and ultimate strain) in warp and weft direction, tensile tests were performed on warp and weft single-yarn specimens, extracted from the grid, with a length of $700 \mathrm{~mm}$. The tests were displacement-controlled using a servo-hydraulic testing machine equipped with a $100 \mathrm{kN}$ load cell. To improve the specimen gripping by the machine, steel tabs were applied to the specimens ends. An extensometer with a gauge length of $50 \mathrm{~mm}$ was used to measure the specimen strain during the test.

The stress-strain curves resulting from the experimental tests are reported in Fig. 2 for weft and warp specimens. The curves showed a linear-elastic behavior up to the brittle specimen failure, which is associated with the glass fiber tensile strength. For some warp specimens, a load drop associated with the failure of a small portion of the twisted bundles was observed close to the peak load. This behavior is caused by
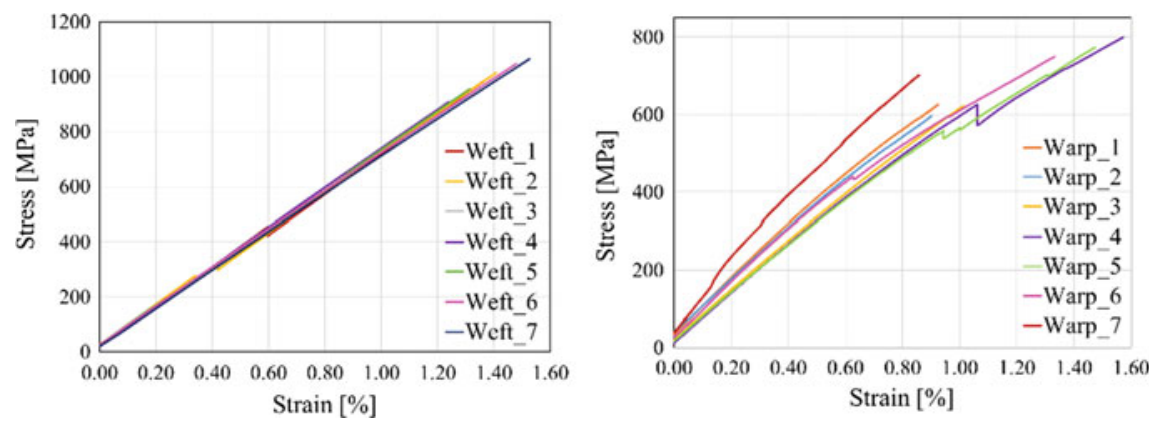

Fig. 2 Stress-strain curves for weft and warp single-yarn specimens 
Table 1 Results of tensile tests on glass fiber weft and warp yarns

\begin{tabular}{l|c|c|l|l|l|l|l}
\hline Sample & $\begin{array}{l}F_{\max } \\
{[\mathrm{kN}]}\end{array}$ & $\begin{array}{l}\sigma_{\max } \\
{[\mathrm{MPa}]}\end{array}$ & $E[\mathrm{GPa}]$ & Sample & $\begin{array}{l}F_{\max } \\
{[\mathrm{kN}]}\end{array}$ & $\begin{array}{l}\sigma_{\max } \\
{[\mathrm{MPa}]}\end{array}$ & $E[\mathrm{GPa}]$ \\
\hline Weft_1 & 7.08 & 1185.9 & 68.51 & Warp_1 & 5.10 & 894.1 & 68.09 \\
\hline Weft_2 & 6.59 & 1103.9 & 68.12 & Warp_2 & 5.06 & 888.5 & 65.02 \\
\hline Weft_3 & 5.17 & 866.0 & 72.74 & Warp_3 & 4.27 & 748.5 & 62.50 \\
\hline Weft_4 & 5.42 & 907.9 & 72.58 & Warp_4 & 4.57 & 800.9 & 61.51 \\
\hline Weft_5 & 5.70 & 954.8 & 68.83 & Warp_5 & 4.41 & 772.9 & 60.04 \\
\hline Weft_6 & 5.94 & 994.9 & 70.01 & Warp_6 & 4.30 & 753.8 & 67.96 \\
\hline Weft_7 & 5.94 & 994.9 & 68.58 & Warp_7 & 4.91 & 861.4 & 79.30 \\
\hline Average & 5.98 & 1001.2 & 69.91 & Average & 4.66 & 817.2 & 66.3 \\
\hline CoV [\%] & 11.1 & 11.1 & 2.8 & CoV [\%] & 7.7 & 7.7 & 9.8 \\
\hline
\end{tabular}

the fiber twisting in warp specimens, which caused stress concentrations where the fibers deviate from linearity. The failure load $F_{\max }$ and the corresponding maximum stress $\sigma_{\max }$ obtained by each test, together with the elastic modulus $E$, are reported in Table 1.

\section{Experimental Program}

A total of 16 tests were performed on two different specimens simulating horizontal slabs strengthened with the glass composite grid described in Sect. 2. Ten tests were conducted on specimens simulating a one-way timber slab, strengthened with the 40 $\times 80 \mathrm{~mm}$ or the $80 \times 80 \mathrm{~mm}$ grid, whereas the remaining six tests were conducted on a pre-stressed RC slab including hollow clay elements, which was strengthened with either the $40 \times 40 \mathrm{~mm}$, the $40 \times 80 \mathrm{~mm}$, or the $80 \times 80 \mathrm{~mm}$ grid.

Specific steel anchors were employed to fix the composite grid to the slab intrados. These steel anchors consist of one expandable anchor and a $50 \mathrm{~mm}$ diameter steel washer and were applied at a distance of $500 \mathrm{~mm}$ from one another. The role of the anchors in the specimen load bearing capacity was investigated by varying a number of parameters: (i) washer material (steel or PE); (ii) local strengthening of the anchor with the application of a single mesh of $40 \times 40 \mathrm{~mm}$ composite grid below the steel washer (Fig. 3).

The tests were conducted in displacement control with a rate of $10 \mathrm{~mm} / \mathrm{min}$ using a hydraulic jack with a capacity of $100 \mathrm{kN}$. To accommodate possible differential displacements or rotations of the slab, the hydraulic jack was equipped with a spherical joint. The vertical displacement of the slab and of the grid was measured with linear variable displacement transducers (LVDTs).

The timber slab was simulated by two laminate timber joists supported by rigid steel supports (Fig. 4). The cross-sectional area of the timber joists was 240 (height) $\times 120$ (width) $\mathrm{mm}$ and the center-to-center distance between them was $600 \mathrm{~mm}$. The 

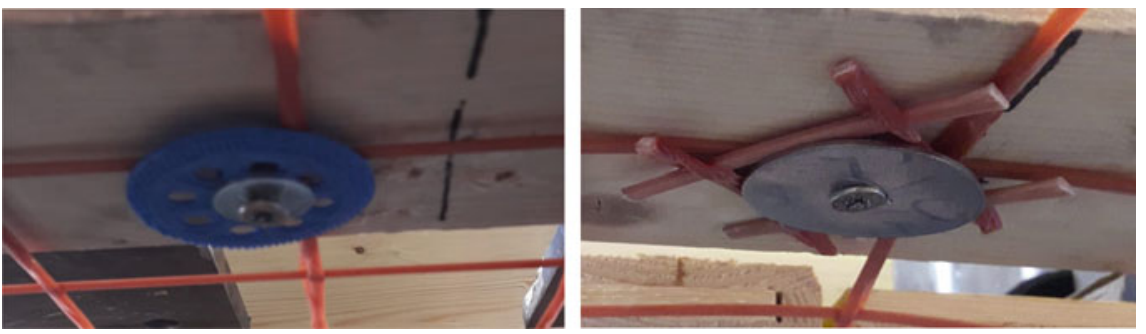

Fig. 3 Anchorage type: anchor with PE washer (left) and anchor with steel washer strengthened using a single mesh of $40 \times 40 \mathrm{~mm}$ composite grid
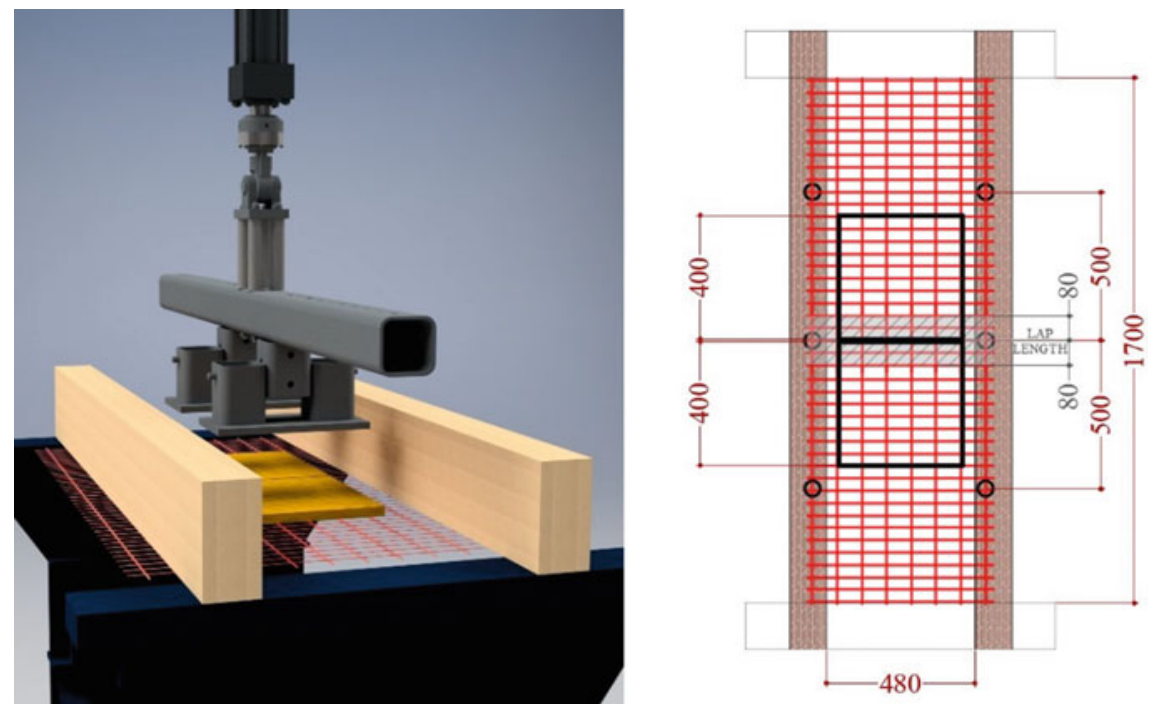

Fig. 4 Tests on strengthened timber slabs (dimensions in $\mathrm{mm}$ )

composite grid was fixed to the joist intrados and the load was applied directly onto it by two contiguous timber footprints with areas of $400 \times 400 \mathrm{~mm}$ (Fig. 4). Two separate load footprints were employed to simulate the contemporary crumbling of two separated hollow clay elements. In these tests, the hydraulic jack was connected to a steel distribution beam. The timber footprints were connected with spherical joints to the steel distribution beam (Fig. 4) and the load was transferred from the jack to the glass composite grid. Four LVDTs were used to measure the vertical displacement at each joist midspan and under the center-point of the footprints. To investigate the effect of grid discontinuity, four tests were conducted on specimens strengthened with two separate grids superimposed for $160 \mathrm{~mm}$ at midspan (Fig. 4). Furthermore, two tests were carried out to analyze the behavior of the different anchors on the grid bearing capacity. 


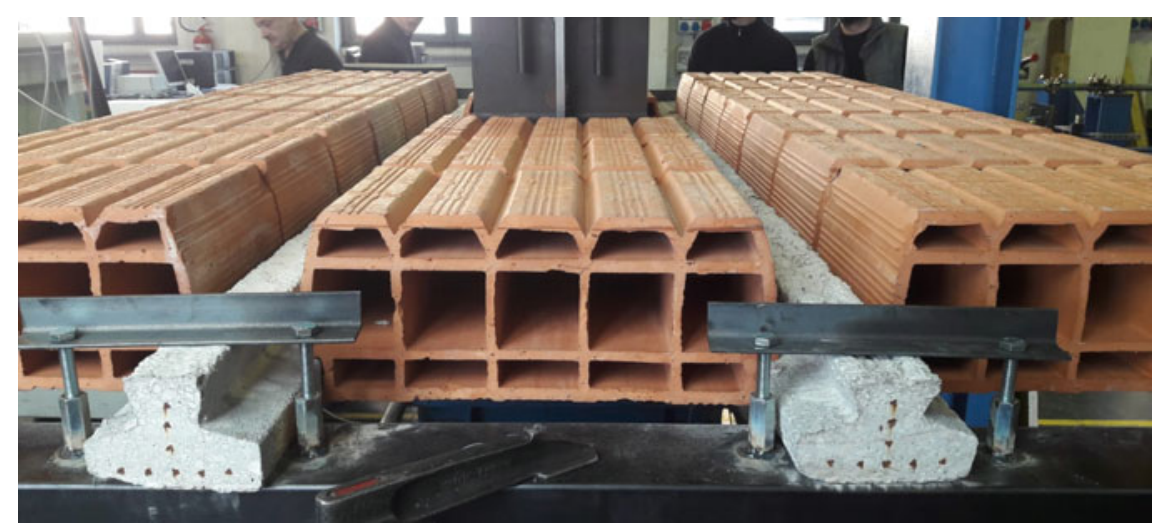

Fig. 5 Cross-section of the pre-stressed RC joists and hollow clay elements

The pre-stressed RC slab with hollow clay elements was composed of four prestressed concrete joists with a center-to-center spacing of $480 \mathrm{~mm}$ fixed to a rectangular steel frame (Fig. 5). The joists supported hollow clay elements placed between the joists themselves. The load was applied to the glass grid with a single timber footprint of dimensions $240 \times 350 \mathrm{~mm}$ through the space of the central hollow element, which was removed. The composite grid was fixed to the joist soffit with either eight steel anchors (specimens type a in Table 2) or four (specimens type b in Table 2) on each of the central joists, spaced at $500 \mathrm{~mm}$ (Fig. 6).

One linear variable displacement transducer was placed under the load footprint to measure the vertical displacement. The vertical deflection of the slab was not measured since it was negligible with regards to grid displacement. To investigate grid capacity, three tests were conducted with the weft yarns aligned with the joists' longitudinal axis and three tests with the warp yarns aligned with the joists' longitudinal axis.

\section{Results and Discussion}

The results of the experimental tests are reported in Table 2. Specimens were named according to the notation Q_XY_Z_d_A_n, where Q (equal to T = "timber" or C $=$ "pre-stressed RC") indicates the slab type, $\mathrm{X}$ and $\mathrm{Y}$ are the grid spacing (in $\mathrm{cm}$ ) in weft an warp direction, respectively, $Z$ is the number of grid layer applied ( 2 in the case of discontinuous grids), $\mathrm{d}$ (equal to $\mathrm{a}=$ weft direction aligned with the slab joist or $\mathrm{b}=$ warp direction aligned with the slab joist) indicates the grid orientation, A (equal to $\mathrm{S}=$ "standard", W = "PE washer", or R = "steel washer") indicates the anchor type, and $\mathrm{n}$ is the specimen number. 
Table 2 Test results

\begin{tabular}{|c|c|c|c|c|}
\hline Name & Max load $[\mathrm{kN}]$ & $\begin{array}{l}\text { Load footprint } \\
{[\mathrm{m} \times \mathrm{m}]}\end{array}$ & $\begin{array}{l}\text { Bearing capacity } \\
{\left[\mathrm{kN} / \mathrm{m}^{2}\right]}\end{array}$ & $\begin{array}{l}\text { Vertical } \\
\text { displacement } \\
{[\mathrm{mm}]}\end{array}$ \\
\hline T_48_1_a_S_1 & 3.40 & $0.40 \times 0.80$ & 10.65 & 50.86 \\
\hline T_48_1_a_S_2 & 3.28 & $0.40 \times 0.80$ & 10.27 & 42.94 \\
\hline Average & 3.34 & - & 10.46 & 46.90 \\
\hline T_88_1_a_S_1 & 1.66 & $0.40 \times 0.80$ & 5.19 & 44.68 \\
\hline T_88_1_a_S_2 & 1.04 & $0.40 \times 0.80$ & 3.26 & 55.75 \\
\hline Average & 1.35 & - & 4.22 & 50.21 \\
\hline T_48_2_a_S_1 & 4.85 & $0.40 \times 0.80$ & 15.16 & 64.35 \\
\hline T_48_2_a_S_2 & 3.93 & $0.40 \times 0.80$ & 12.30 & 58.56 \\
\hline Average & 4.39 & - & 13.73 & 61.46 \\
\hline T_88_2_a_S_1 & 2.23 & $0.40 \times 0.80$ & 6.99 & 46.76 \\
\hline T_88_2_a_S_2 & 1.99 & $0.40 \times 0.80$ & 6.22 & 72.16 \\
\hline Average & 2.11 & - & 6.60 & 59.46 \\
\hline T_88_1_a_W_1 & 1.49 & $0.40 \times 0.80$ & 4.66 & 58.45 \\
\hline T_88_1_a_R_2 & 1.52 & $0.40 \times 0.80$ & 4.76 & 53.46 \\
\hline C_44_1_a_S & 4.02 & $0.35 \times 0.24$ & 47.92 & 97.84 \\
\hline C_44_1_b_S & 2.76 & $0.35 \times 0.24$ & 32.92 & 105.26 \\
\hline C_48_1_a_S & 1.56 & $0.35 \times 0.24$ & 18.64 & 65.89 \\
\hline C_48_1_b_S & 2.11 & $0.35 \times 0.24$ & 25.14 & 104.16 \\
\hline C_88_1_a_S & 1.32 & $0.35 \times 0.24$ & 15.71 & 105.36 \\
\hline C_88_1_b_S & 1.38 & $0.35 \times 0.24$ & 16.42 & 81.38 \\
\hline
\end{tabular}
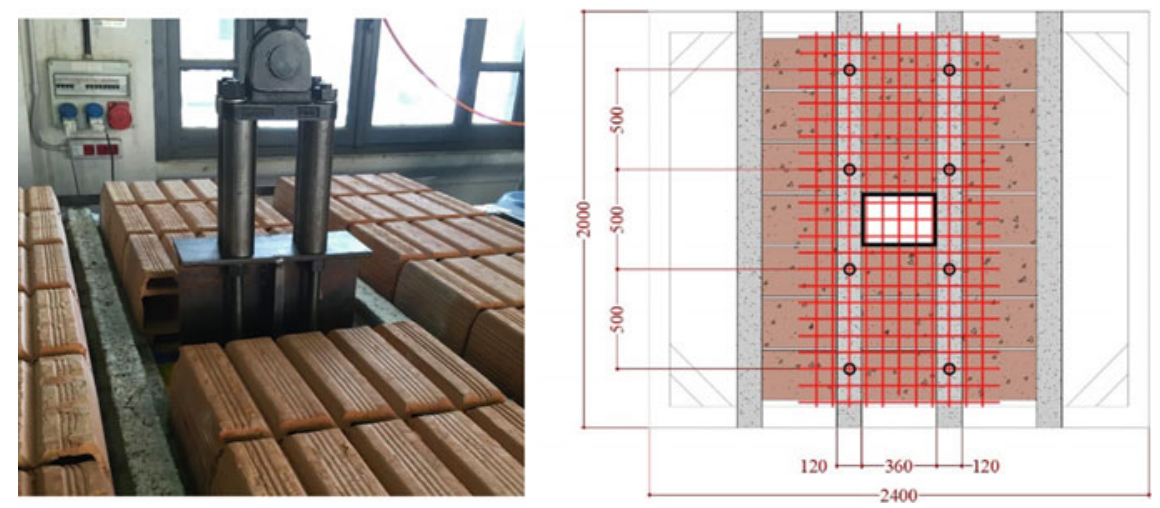

Fig. 6 Tests on strengthened pre-stressed RC slabs (dimensions in mm) 
Table 2 reports the maximum load, bearing capacity (i.e. the maximum applied load divided by the area of a single footprint), and the associated vertical displacement. Figure 7 shows the load-displacement curves for timber slabs strengthened with grids with $40 \times 80 \mathrm{~mm}$ and $80 \times 80 \mathrm{~mm}$ mesh. All the specimens show an initial approximately linear behavior, which ends with a marked load drop associated with the shear failure of one of the weft or warp yarns close to one of the anchors (Fig. 8). After this load drop, with increasing displacement, the applied load further increased in some cases and remained approximately constant in others due to stress redistribution in the grid bundles.

Specimens strengthened with discontinuous grids showed similar load bearing capacity, although a decrease of the maximum load was observed for some specimens (see Table 2). Also in these tests, the stress redistribution in the grids allowed for an increase in the applied displacement maintaining or even increasing the applied load. This behavior is particularly important in the case of seismic events because it may prevent the sudden collapse of the slab intrados.

All specimens eventually failed due to grid shear rupture close to the anchors due to stress concentrations at the grid warp-weft joints. To decrease the stress concentration at the joints, a single $40 \times 40 \mathrm{~mm}$ grid mesh was inserted under the
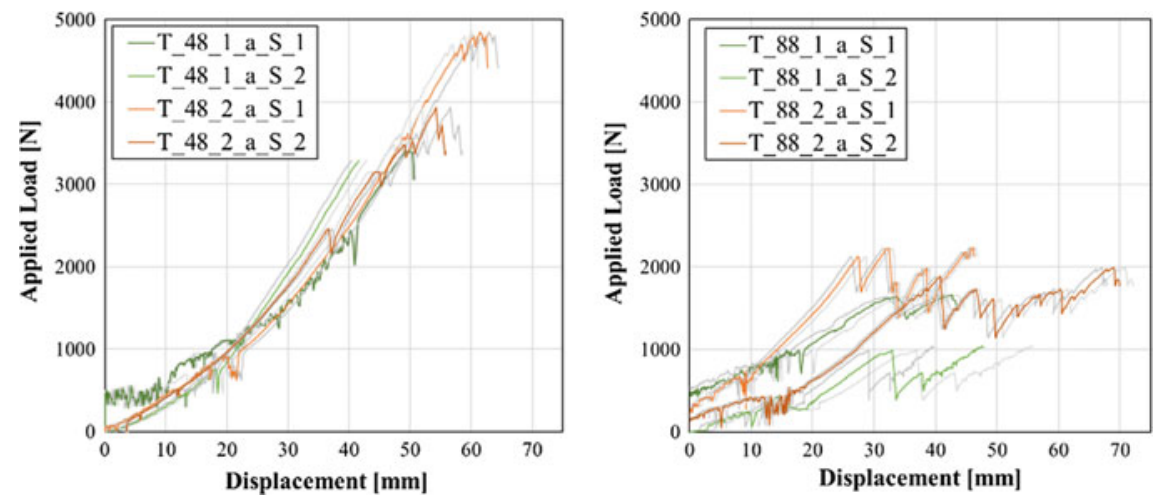

Fig. 7 Load-displacement curves of timber slabs strengthened with a single continuous grid and two discontinuous grids
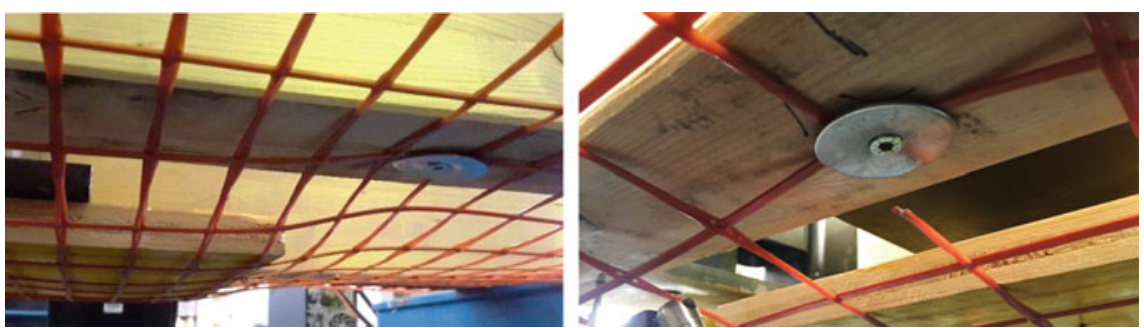

Fig. 8 Typical grid shear failure at anchor positions 
steel washer (Fig. 3). In addition, the steel washer was substituted with a PE washer to investigate the effect of washer stiffness on the response obtained. Figure 9 shows the load responses of timber slabs strengthened with a single continuous grid with 80 $\times 80 \mathrm{~mm}$ mesh with different anchorages (i.e. different washers and the addition of the strengthening single grid mesh). The results show that the different anchorages proposed did not significantly affect the specimen bearing capacity.

The results of the tests conducted on pre-stressed RC slabs are reported in Fig. 10. Specimens strengthened with the $40 \times 40 \mathrm{~mm}$ grid showed a higher bearing capacity for specimens with warp laminated yarns oriented orthogonally to the slab joist direction with respect to specimens with weft pultruded elements oriented orthogonally to the slab joist direction. As observed for timber slabs, pre-stressed RC slabs strengthened with $40 \times 80 \mathrm{~mm}$ and $80 \times 80 \mathrm{~mm}$ grids provided similar results (Fig. 10).

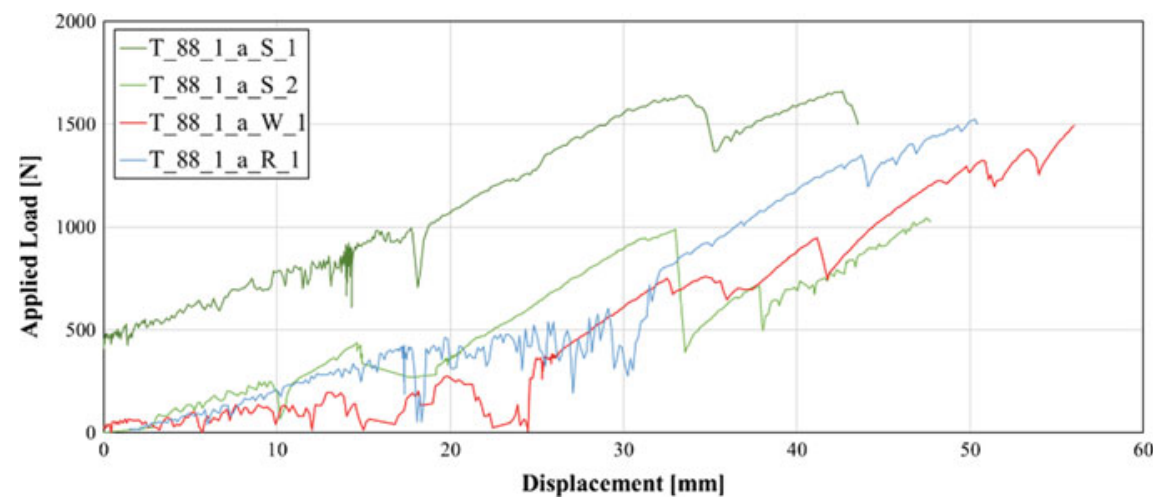

Fig. 9 Load-displacement curves for timber slabs with different anchors

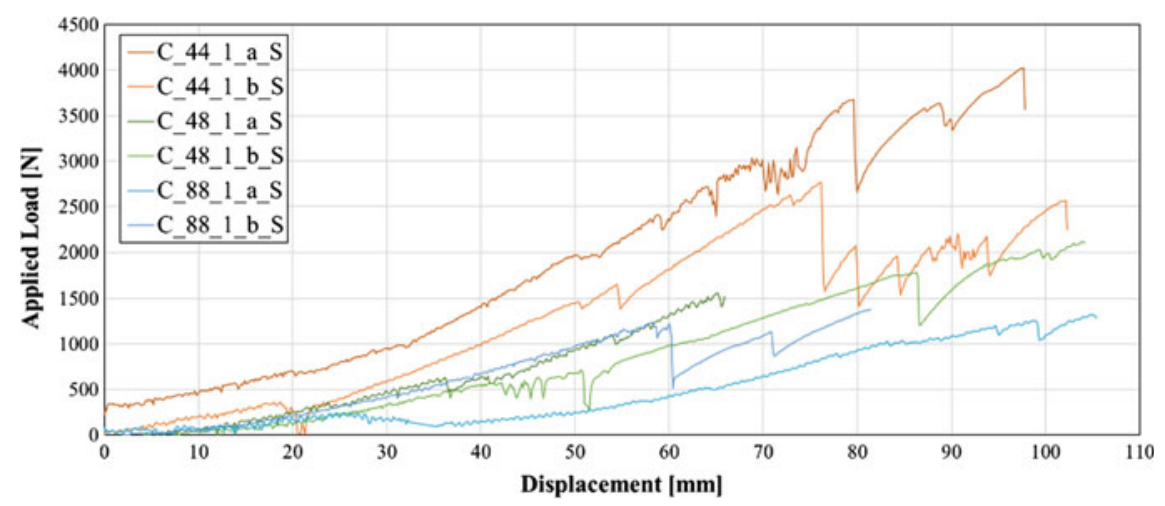

Fig. 10 Load-displacement curves for pre-stressed RC slabs 


\section{Conclusions}

This paper described the results of 16 experimental punching tests on different specimens simulating horizontal slabs, namely timber and pre-stressed RC slabs, strengthened with a glass fiber-reinforced polymer (FRP) grid designed as the reinforcement of a composite-reinforced mortar (CRM). The tests were designed to obtain information on the efficiency of a glass FRP grid in preventing and contrasting the occurrence of slab intrados failure and crumbling. The parameters investigated were the grid spacing, anchorage types, and grid discontinuity. The results obtained showed that a shear failure of a grid bundle close to one anchor always occurred. However, this bundle failure did not determine the specimen failure, because the stress redistribution in the grid allowed for maintaining and in some cases increasing the applied load. All grid spacings $(40 \times 40 \mathrm{~mm}, 40 \times 80 \mathrm{~mm}$, and $80 \times 80 \mathrm{~mm})$ demonstrated similar behavior. The different anchors studied (i.e. steel anchors with steel and PE washer and with the addition of a single mesh grid strengthening below the washer) did not significantly affect the behavior observed. Finally, the grid discontinuity did not significantly affect the load-bearing capacity.

The results obtained showed that the glass grid studied is an efficient solution to solve intrados crumbling hazards and, due to the speed of the intervention, is particularly attractive for applications in public buildings, such as educational buildings, which cannot remain closed for long period.

Acknowledgements TCS s.r.l. is gratefully acknowledged for providing the strengthening materials and for preparing the experimental specimens.

\section{References}

de Felice G, De Santis S, Garmendia L, Ghiassi B, Larrinaga P, Lourenco PB et al (2014) Mortarbased systems for externally bonded strengthening of masonry. Mater Struct 47:2021-2037

Bakis CE, Bank LC, Brown VL, Cosenza E, Davalos JF, et al (2002) Fiber-reinforced polymer composites for construction-state-of-the-art review. J Compos Constr 6(2):73-87

ACI 549.4R (2013) Guide to design and construction of externally bonded fabric-reinforced cementitious matrix (FRCM) systems for repair and strengthening concrete and masonry structures. American Concrete Institute, Farmington Hills, MI

CNR-DT 215 (2019) Istruzioni per la Progettazione, l'Esecuzione ed il Controllo di Interventi di Consolidamento Statico mediante l'utilizzo di Compositi Fibrorinforzati a matrice inorganica. Italian National Research Council, Rome, Italy

D'Antino T, Carozzi FG, Poggi C (2019) Diagonal compression of masonry walls strengthened with composite reinforced mortar. In: Proceeding of mechanics of masonry structures strengthened with composite materials

Carozzi FG, Bellini A, D’Antino T, de Felice G, Focacci F, Hojdys L, Laghi L et al (2017) Experimental investigation of tensile and bond properties of carbon-FRCM composites for strengthening masonry elements. Compos B Eng 128:100-119 
Open Access This chapter is licensed under the terms of the Creative Commons Attribution 4.0 International License (http://creativecommons.org/licenses/by/4.0/), which permits use, sharing, adaptation, distribution and reproduction in any medium or format, as long as you give appropriate credit to the original author(s) and the source, provide a link to the Creative Commons license and indicate if changes were made.

The images or other third party material in this chapter are included in the chapter's Creative Commons license, unless indicated otherwise in a credit line to the material. If material is not included in the chapter's Creative Commons license and your intended use is not permitted by statutory regulation or exceeds the permitted use, you will need to obtain permission directly from the copyright holder.

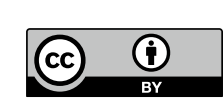

